\title{
CULTURA ESCOLAR E CULTURA POLÍTICA: PROJETO DE NACIONALIZAÇÃO E O JORNAL ESCOLAR A CRIANÇA BRASILEIRA (SANTA CATARINA, 1942-1945)
}

\author{
Cristiani Bereta da Silva \\ Universidade do Estado de Santa Catarina, Brasil.
}

$\cos 8$

Resumo

O presente artigo problematiza as relações estabelecidas entre o projeto político de nacionalização em Santa Catarina e as práticas escolares a partir da análise do jornal escolar $A$ Criança Brasileira. Esse periódico foi publicado por 27 anos, de 1942 a 1968, assinado sempre por alunos do Primário e do Curso Complementar do Grupo Escolar Lauro Müller, inaugurado em 1912, em Florianópolis. Para essa discussão foram selecionados os números publicados entre 1942 e 1945. Tal escolha foi feita em razão dos temas privilegiados: biografias, datas comemorativas, notícias do cotidiano da escola, principalmente aquelas referentes às associações auxiliares, que evidenciam as práticas nacionalistas do período. Essas questões serão interpretadas a partir das noções de cultura política e de cultura escolar. Postula-se que o entrecruzamento dessas noções permitirá melhor compreender a permeabilidade entre as práticas políticas e as práticas escolares cotidianas, bem como quais normas e valores contribuíram para determinar as representações que os sujeitos e coletividades do passado fizeram de si mesmos e intentaram legar ao futuro. Palavras-chave: cultura escolar, cultura política, nacionalização.

\section{THE CULTURE OF SCHOOL AND POLITICAL CULTURE:THE NATIONALIZATION PROJECT AND THE SCHOOL NEWSPAPER A CRIANÇA BRASILEIRA} (SANTA CATARINA, 1942-1945)

\begin{abstract}
This article presents the issue of relations established between the political nationalization project in the state of Santa Catarina and school practices, departing from the analysis of $A$ Criança Brasileira, a school newspaper. Such newspaper was published for 27 years (from 1942 to 1968), being always signed by Elementary and Complementary school students of a state school, Grupo Escolar Lauro Müller, established in 1912 in the city of Florianópolis. For the present discussion, issues published between 1942 and 1945 have been selected. Such choice has been done based on the privileged topics of the period: Biographies, celebratory dates, school life news - particularly those related to aid institutions that bring to light nationalist practices. Such issues will be interpreted based on notions of political culture, and the culture of school environments. The intertwining of such notions is postulated to avail a better understanding of how political practices
\end{abstract}


permeate quotidian school practices, as well as which norms and values have contributed to determining a representation that past subjects and collectivities have made of themselves, and have attempted to leave as future legacy.

Keywords: culture of school, political culture, nationalization.

\section{CULTURA ESCOLAR Y CULTURA POLÍTICA: PROYECTO DE NACIONALIZACIÓNY EL PERIÓDICO ESCOLAR A CRIANÇA BRASILEIRA} (SANTA CATARINA, 1942-1945)

\section{Resumen}

A partir del análisis de periódico escolar A Criança Brasileira, este artículo problematiza las relaciones establecidas entre el proyecto político de nacionalización en Santa Catarina y las prácticas escolares. Dicho periódico fue publicado a lo largo de 27 años, de 1942 a 1968, firmado siempre por alumnos de enseñanza básica y del Curso Complementario del Grupo Escolar Lauro Müller, inaugurado en 1912 en Florianópolis. Para la presente discusión, se han seleccionado los números publicados entre 1942 y 1945. Esta elección se dio en función de los temas privilegiados: biografías, fechas conmemorativas, noticias del cotidiano escolar, principalmente las que se refieren a las asociaciones auxiliares, que evidencian prácticas nacionalistas en ese periodo. Estas cuestiones se interpretarán partiendo de las nociones de cultura política y cultura escolar. Se postula que el entrecruce de estas nociones permitirá comprender mejor la permeabilidad entre las prácticas políticas y las prácticas escolares cotidianas, así como cuáles las normas y valores que contribuyeron para determinar las representaciones que los sujetos y colectividades del pasado han hecho de si mismos y trataron de dejar para el futuro.

Palabras clave: cultura escolar, cultura política, nacionalización.

\section{CULTURE SCOLAIRE ET CULTURE POLITIQUE:LE PROJET DE NATIONALISATIONET LE JOURNAL SCOLAIRE A CRIANÇA BRASILEIRA (SANTA CATARINA, 1942-1945)}

\section{Résume}

Cet article questionne les relations établies entre le projet politique de nationalisation en Santa Catarina et les pratiques scolaires à partir de l'analyse du journal scolaire $A$ Criança Brasileira. Ce périodique a été publié pendant 27 ans, de 1942 à 1968. II a toujours été rédigé par des élèves de l'enseignement primaire et par des élèves du cours complémentaire du groupe scolaire Lauro Müller, qui existe depuis 1912 à Florianópolis. Dans le cadre de cette discussion, des publications entre 1942 et 1945 ont été sélectionnées. Ce choix se justifie par des thèmes qui ont été abordés durant cette période comme des biographies, dates commémoratives et nouvelles du quotidien de l'école, à savoir les nouvelles des associations auxiliaires qui mettaient en relief les pratiques nationales. Ces questions seront interprétées à partir de la notion de la culture politique et de la culture scolaire. On suppose que l'entrecroisement de ces notions permettra de mieux comprendre la perméabilité qui existe entre les pratiques politiques et les pratiques scolaires quotidiennes. Aussi, il permettra de mieux saisir quelles normes et valeurs ont contribué à déterminer la représentation que les sujets et les collectivités ont eu d'eux-mêmes auparavant. Il sera également possible de voir quelles normes et valeurs qu'ils ont essayé de transmettre à l'avenir.

Mots-clé: culture scolaire, culture politique, nationalisation. 


\section{Introdução}

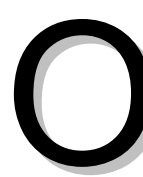

dia $1^{\circ}$ de maio de 1942 marcou a publicação do primeiro número do jornal $A$ Criança Brasileira, órgão mensal do Grupo Escolar Lauro Müller ${ }^{1}$. Impresso em gráfica, em preto e branco, com formato que lembra o de um tabloide ${ }^{2}, \mathrm{o}$ jornal foi assim apresentado pela aluna Zita Calado Flores:

Este jornal se publica hoje pela primeira vez. Ele tratará de vários assuntos e da vida da nossa escola. Foi fundado no Dia da Criança, às 9 horas. [...] Devemos lembrar sempre desta data e trabalhar com alegria para que a nossa Escola seja a primeira. Este jornal fará tudo o que for possível para conseguirmos isso. Nele colaborarão todos os alunos deste estabelecimento tanto do curso fundamental, como o do curso complementar. ${ }^{3}$ ( $A$ Criança Brasileira, n. 1, 1ำ maio 1942)

A singeleza do texto não oculta o fato de que a escola estava inserida num campo de forças e de intersecção entre práticas políticas e práticas escolares. Além disso, dá o tom do lugar que esse jornal ocuparia no cotidiano do Grupo Escolar Lauro Müller a partir de então: instrumento valioso para que a escola seja a primeira. Postulado que dá a ler a importância de tal investimento: legitimar-se como escola modelo, integrada aos anseios do projeto político daquele momento, como quando foi fundada, cerca de 30 anos antes.

$\mathrm{Na}$ capa a apresentação do jornal exibia uma fotografia centralizada de Getúlio Vargas, seguida de texto elogioso que enfatizava o aniversário do presidente, ocorrido no dia 19 de abril, bem como suas contribuições para o "bem do povo e o progresso da nação" (Maria C. Fracalazzi, $1^{\circ}$ ano C). Na sequência, vê-se a fotografia de Nereu Ramos, governador de Santa Catarina a partir de 1935 e interventor federal entre 1937 e 1945, quase na mesma proporção e distribuição na página que aquela de Vargas, acompanhada pela nota:

No dia $1^{\circ}$ de maio comemora-se o "Dia do Operário", é justo que seja comemorada tal data, pois o operário engrandece a nação e é fator de progresso. Também nesse dia comemora-se mais um aniversário do próspero governo do Dr. Nereu Ramos, DD. Interventor Federal em nosso Estado. A ele devemos o desenvolvimento, sempre crescente, do Estado de Santa Catarina. (Luiza Doin Vieira, $1^{\circ}$ ano C, p. 3)

A organização dos elementos gráficos e o destaque dado às fotografias publicadas nesse número de lançamento do jornal podem ser observados nas reproduções a seguir.

\footnotetext{
${ }^{1}$ Os números localizados desse jornal pertencem ao acervo do Museu da Escola Catarinense - Udesc.

${ }^{2}$ Formato de jornal surgido em meados do século 20 , no qual cada página mede, aproximadamente, $33 \mathrm{cmx}$ $28 \mathrm{~cm}$.

${ }^{3}$ Com o objetivo de facilitar a leitura, todas as citações deste artigo retiradas de publicações da década de 1940 tiveram a grafia atualizada, de acordo com as atuais normas da língua portuguesa.
} 
Figura 1

Getúlio Vargas e Nereu Ramos.
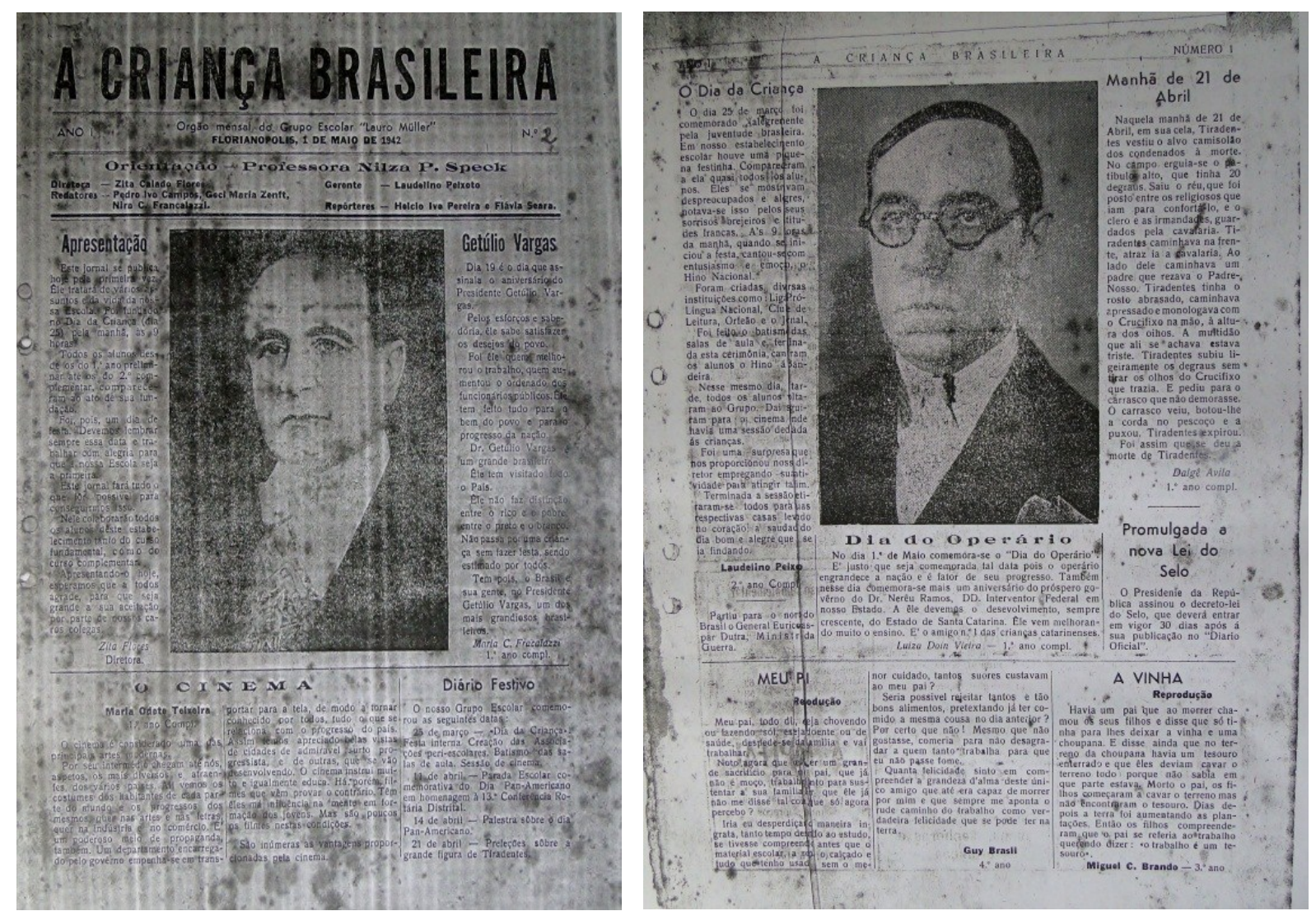

Fonte: A Criança Brasileira, n. 1, 1ํㅡaio, 1942.

A distribuição dos textos em torno das fotografias, a escolha do simbólico dia $1^{\circ}$ de maio para a publicação do primeiro número do jornal, as fotografias de Getúlio Vargas e Nereu Ramos, acompanhadas dos respectivos textos, instalam algumas questões que nortearão a discussão proposta neste artigo.

O que significa ser a primeira escola, desejo anunciado na apresentação? $E$ os destaques dados a Getúlio Vargas e Nereu Ramos na publicação do primeiro número do jornal? O que nos dizem os textos, as fotografias e os anúncios publicitários distribuídos nas páginas do jornal sobre o cotidiano do Grupo Escolar Lauro Müller? O que ele pode nos dizer sobre as práticas políticas e escolares desse momento histórico? Ou melhor, qual passado o jornal $A$ Criança Brasileira permite acessar?

Antes de me ater ao exercício que buscará responder a essas questões, ou pelo menos problematizá-las, considero imprescindível localizar o lugar de onde falo a fim de melhor situar as escolhas teóricas e metodológicas que fiz. Para Michel de Certeau (1982), a particularidade do lugar é marca indelével na operação historiográfica. São as escolhas do historiador que ligam as ideias aos lugares, numa operação marcada por três fases: escolha das fontes, procedimentos de análise e escrita da história (Certeau, 1982). São itinerários de pertinências que não devem ocultar o fato de que, ainda assim, são operações que envolvem escolhas. Explicitar as escolhas realizadas é uma forma de indicar as possibilidades e os limites desse texto. 
Nessa direção, entendo que o jornal $A$ Criança Brasileira não deve ser analisado isolado do conjunto de monumentos do qual faz parte. $\mathrm{Na}$ condição de um documento/monumento (Le Goff, 2003), ele é um instrumento de poder, reificado por duas razões objetivas. Em primeiro lugar, porque é resultado do esforço dos sujeitos do passado - professores, estudantes do Grupo Escolar Lauro Müller e demais sujeitos a ele relacionados, o que evidentemente inclui autoridades políticas e intelectuais - de legar ao futuro uma imagem de si próprios. Em segundo lugar, porque o selecionei para ser interpretado e fornecer indícios sobre acontecimentos passados.

A Criança Brasileira é um jornal escolar e, como tal, pode ser entendido como parte da imprensa pedagógica, ou seja, como parte de um conjunto de publicações que pode ser feita por docentes para docentes, por estudantes ou docentes para estudantes ou docentes, ou ainda pelo Estado ou outras instituições (Bastos, 2002). No caso em questão, parece que o jornal era publicado por estudantes, com fortes indícios de receber orientação e contribuição de docentes e até de alguns pais, para a comunidade escolar estudantes, docentes, familiares e outras escolas -, pois há evidências de circulação desse jornal em outros grupos escolares no período.

Qualificado como imprensa escolar ou estudantil, é ainda assim um impresso periódico, cujo suporte, o jornal, impõe desafios metodológicos ao historiador. O mais importante deles, trabalhado por Tania Regina de Luca (2006), consiste em evitar a armadilha de recortar palavras, imagens ou textos inteiros desvinculados de uma determinada realidade e contexto. Ou, ainda, observar as narrativas apenas na dispersão sem relacioná-las ao conjunto de discursos que as enunciam e as legitimam.

Como impresso periódico, esse jornal também selecionou, ordenou, estruturou e narrou de determinada forma aquilo que se elegeu como digno de chegar até seu público (Luca, 2006). Partindo dessa consideração, o esforço aqui empreendido foi o de analisar A Criança Brasileira a partir da sua materialidade, circunstanciada em sua condição de periódico impresso estudantil, projeto coletivo situado num contexto histórico, articulado a determinado grupo e interesses. São esses indícios que me permitirão levar a cabo a terceira fase da operação historiográfica: a escrita, exercício capaz apenas de produzir uma representação do passado, não de recuperá-lo ou mesmo contá-lo tal como ele foi.

\section{Uma escola, um jornal e um projeto: a construção da nacionalidade}

O Grupo Escolar Lauro Müller ${ }^{4}$ foi o primeiro fundado em Florianópolis e o segundo no Estado de Santa Catarina. Sua inauguração, em 24 de maio de 1912, foi um acontecimento na cidade. Não faltaram pompa nem circunstância à cerimônia e dela participaram autoridades locais e estaduais, sendo os mais importantes o próprio governador Vidal Ramos e o professor Orestes Guimarães ${ }^{5}$, responsável pela reforma da instrução pública no Estado (1911-1935).

Localizado no centro da cidade, área nobre, próximo ao Palácio do Governo e da Catedral Metropolitana, o Grupo destacava-se pela arquitetura moderna e as autoridades

\footnotetext{
${ }^{4} \mathrm{~A}$ escola continua em funcionamento até a presente data e oferece Ensino Fundamental e o Médio.

${ }^{5}$ Nota do editor: sobre Orestes Guimarães ver MARTINS, Elizabeth; SILVA, Vera Lucia Gaspar da. A atuação de Cacilda Guimarães: lugares e fazeres (Santa Catarina, 1907-1931). Hist. Educ. (Online). Porto Alegre: Asphe, v. 16, n. 36, 2012, p. 121-138.
} 
locais não hesitavam em exibi-lo como prova da modernidade catarinense. Sua localização privilegiada e utilização como campo de prática de ensino da Escola Normal Catarinense, bem como os altos investimentos recebidos na sua construção e na aquisição dos modernos móveis e utensílios escolares, o converteram "na menina dos olhos do governador e sala de visitas para educadores e autoridades diversas, que registravam as suas impressões elogiosas, no livro de visitas" (Teive; Dalabrida, 2011, p. 39).

Por essas e outras razões postula-se que esse Grupo talvez seja uma das instituições escolares fundadas no início do século 20, no Estado, que mais representa a força política instaurada para a divulgação de um ideal de escola, de povo brasileiro e de nação. Essas questões estão contidas na elaboração dos projetos de nacionalização do ensino, iniciado em Santa Catarina em 1911, com a reforma da instrução pública, sob a responsabilidade de Orestes Guimarães. Mas esse processo tem sua dinâmica modificada na década de 1930, principalmente com a instalação do Estado Novo. Nas décadas de 1930 e 1940 as propostas de nacionalização de ensino passaram a enfatizar a afirmação da identidade nacional brasileira e contaram com intervenções de forma mais contundentes, principalmente nos estabelecimentos de ensino primário (Campos, 2004). Ressalte-se que à educação hipotecava-se a responsabilidade de civilizar, regenerar a raça, caminho indispensável ao progresso e à modernidade da nação.

O jornal escolar A Criança Brasileira foi publicado regularmente por 27 anos, de 1942 a 1968, assinado sempre por alunos do Curso Primário e do Curso Complementar ${ }^{6}$ do Grupo Escolar Lauro Müller. Os números localizados do jornal podem ser observados no quadro a seguir.

\section{Quadro 1}

Exemplares do jornal A Criança Brasileira localizados.

\begin{tabular}{|c|l|c|c|c|c|}
\hline Anos & \multicolumn{1}{|c|}{ Números } & Exemplares & Anos & Números & Exemplares \\
\hline 1942 (Ano I) & $1,2,3,4-5$ & 4 & 1953 (Ano XII) & $\begin{array}{c}71-72 ; 73-74- \\
75\end{array}$ & 2 \\
\hline 1943 (Ano II) & $6,7-8$ & 2 & 1954 (Ano XIII) & $76-77$ & 1 \\
\hline 1944 (Ano III) & $\begin{array}{l}9-10, \quad 11-12, \\
13-14,15-16\end{array}$ & 4 & 1955 (Ano XIV) & $78-79$ & 1 \\
\hline 1945 (Ano IV) & $25-26$ & 1 & 1956 (Ano XV) & $80-81$ & 1 \\
\hline
\end{tabular}

\footnotetext{
${ }^{6}$ Os cursos ou escolas complementares foram criados com o objetivo de evitar que os egressos dos grupos escolares que ainda não tivessem a idade mínima, 18 anos para os homens e 16 anos para as mulheres, ingressassem na Escola Normal mas, principalmente, para formar professores para as escolas isoladas. Os alunos que concluíssem o curso primário de três anos nas escolas isoladas poderiam matricular-se no $4^{-}$ano dos grupos escolares. Aqueles que concluíssem os quatro anos dos grupos escolares poderiam matricular-se nos cursos complementares, podendo, após sua conclusão, ingressar no $3^{\circ}$ ano da escola normal. Outro dado importante é que, a exemplo dos grupos escolares, os cursos complementares só eram criados nos maiores centros urbanos, pois eram direcionados aos egressos dos grupos escolares, deviam funcionar nos seus prédios e ter como mestres os próprios professores dos grupos, inclusive o mesmo diretor (Teive, 2008, p. 97-98).
} 


\begin{tabular}{|l|l|c|c|c|c|}
\hline 1946 (Ano V) & $\begin{array}{l}27-28 ; 29-30 ; \\
33-34\end{array}$ & 3 & $1957($ Ano XV7) & $82-83$ & 1 \\
\hline 1947 (Ano VI) & $\begin{array}{l}35-36 ; 37-38 ; \\
39-40 ; 41-42\end{array}$ & 4 & 1958 (Ano XVI) & $84-85$ & 1 \\
\hline $\begin{array}{l}4948 \text { (Ano } \\
\text { VII) } \\
47-44 ; 45-46 ;\end{array}$ & 3 & 1959 (Ano XVII) & $86-87$ & 1 \\
\hline $\begin{array}{l}1949 \text { (Ano } \\
\text { VIII) }\end{array}$ & $\begin{array}{l}49-50 ; 51-52 ; \\
53-54\end{array}$ & 3 & 1960 (Ano XVIII) & $88-89$ & 1 \\
\hline 1950 (Ano IX) & $\begin{array}{l}55-56 ; 57-58 ; \\
59-60\end{array}$ & 3 & 1962 (Ano 20) & $90-91$ & 1 \\
\hline 1951 (Ano X) & $\begin{array}{l}61-62 ; 63-64- \\
65\end{array}$ & 2 & 1968 (Ano 20IX) & 96 & 1 \\
\hline 1952 (Ano XI) & $\begin{array}{l}66-67 ; 68-69- \\
70\end{array}$ & 2 & & & \\
\hline
\end{tabular}

Fonte: Acervo do Museu da Escola Catarinense.

Esse jornal compõe o universo do Grupo Escolar Lauro Müller, constitui parte de uma rede de documentos que o descreve, ao mesmo tempo em que representa formas de habitar e atribuir legitimidade a todo um mundo, a partir de uma "rede paralela de significações" (Fernandes, 2005, p. 24). Vista dessa forma, a escola não se reduz apenas a lugar de ensino ou de objetos, mas se constitui, especialmente, como "um mundo de pessoas e um tecido de relações interpessoais" (Ibid., p.24). A análise do jornal, portanto, é indissociável desse lugar social, espaço qualificado, no sentido de que delimita e requer igualmente determinados comportamentos e atitudes geradoras de valores. Nessa condição de espaço qualificado, o grupo escolar define-se também "pela aceitação ou pela produção de estruturas e subestruturas educacionais" (Ibid., p. 20), caracterizandose por ser uma estrutura de normalização.

Como prática escolar, o jornal pertenceu a um contexto de nacionalização bastante diferente daquele de 1912, pois, em 1942, estava-se em pleno Estado Novo, período de recrudescimento do nacionalismo e de forte intervenção governamental em toda a sociedade. Além disso, a entrada do Brasil na Segunda Guerra Mundial, em 22 de agosto de 1942, assinala, no Estado de Santa Catarina, a construção de um clima de medo e de preconceitos contra os imigrantes estrangeiros e seus descendentes.

O exercício proposto neste artigo reside em problematizar as relações estabelecidas entre o projeto político de nacionalização em Santa Catarina e as práticas escolares a partir da análise do jornal escolar A Criança Brasileira. Para realizar essa discussão foram selecionados os números que cobrem quatro anos do jornal, de 1942 a 1945. Tal escolha deve-se ao fato de que os temas mais abordados no período - biografias, datas comemorativas, notícias do cotidiano da escola, principalmente aquelas referentes às associações auxiliares - voltavam-se fortemente para as práticas nacionalistas e suas repercussões, chaves da busca da nova ordem. Esse periódico escolar atuou como veículo de nacionalização, no sentido de que divulgava, ao mesmo tempo que exaltava, o amor à pátria e as ações de cunho cívico-patriótico para a comunidade escolar.

\footnotetext{
${ }^{7}$ As edições dos anos de 1956 e 1957 foram publicadas como número 15.
} 
A perspectiva apresentada é a promoção de uma leitura histórica do jornal, por meio da cultura política e da cultura escolar. Parto do entendimento de que a cultura escolar não pode ser analisada sem que sejam estabelecidas relações que ela mantém, em cada tempo histórico, com o conjunto de culturas que lhe são contemporâneas. Optei, então, por articulá-la à cultura política. Dominique Julia (2001) descreve a cultura escolar como um conjunto de normas e práticas "que definem conhecimentos a ensinar e condutas a inculcar, e que permitem a transmissão desses conhecimentos e a incorporação desses comportamentos" (p. 10).

Para Serge Bernstein (1998, p. 353), "a cultura política, como a própria cultura, se inscreve no quadro das normas e dos valores que determinam a representação que uma sociedade faz de si mesma, do seu passado, do seu futuro". A cultura política é um fenômeno da duração que surge em meio às respostas dadas a uma sociedade "aos grandes problemas e às grandes crises da sua história" (Ibid., p. 355). Neste artigo privilegiam-se as práticas e a inteligibilidade desse conjunto específico, que passa pela compreensão do coletivo de sujeitos que dele fazem parte, o constituem e o dotam de legitimidade, num determinado tempo histórico. O jornal faz parte desse conjunto de práticas que permite ler os conflitos e negociações entre cultura escolar e cultura política.

O contexto histórico analisado remete à construção e consolidação de nova cultura política do regime republicano pós-1930. Contudo, importa notar que a cultura política estado-novista não pode ser observada ou reduzida ao curto período de oito anos, pois, ao demarcar a instalação de um modelo de Estado autoritário, centralizado politicamente, cujo intervencionismo sobre a sociedade foi crescente, ela se articula a transformações e demais políticas que reverberaram na divulgação de normas e valores sobre o comportamento políticos de sujeitos individuais e coletivos (Gomes, 2007). Analisar as práticas e as representações que as designam a partir desse aporte conceitual é importante, na medida em que se compreende que as culturas políticas exercem papel fundamental na legitimação de regimes ou na criação de identidades. A construção de uma cultura política implica a eleição de uma dada memória e de certa leitura política do passado (Abreu et al., 2007).

Pensar as narrativas do jornal escolar $A$ Criança Brasileira, a partir do entrecruzamento entre as culturas política e escolar, constitui possibilidades de dotar de inteligibilidade o modo como se manifesta e se evidencia o projeto de sociedade compartilhado pelo Grupo Escolar Lauro Muller no Estado Novo. Isso porque as culturas políticas exercem papel fundamental na legitimação de regimes ou na criação de identidades. O lugar social ocupado por esse impresso possibilita essa leitura na medida em que, ao veicular opiniões e informações sobre questões pedagógicas, sobre as relações entre estudantes, docentes e direção, sobre as turmas, bem como sobre outros grupos escolares, o jornal informa valores e projetos coletivos os quais compartilha.

Ser a primeira escola, desejo anunciado em seu lançamento, poderia significar a necessidade de o Grupo Escolar Lauro Müller evidenciar sua ligação com as autoridades que representavam as instâncias de poder locais, estaduais e nacionais, por meio de insígnias, ritos e símbolos. Significava empreender esforços para demonstrar sua integração ao projeto de construção da nacionalidade. Não por acaso, o lançamento do 
jornal trazia em grande destaque as fotografias do presidente Getúlio Vargas e de Nereu Ramos, como já visto.

Certamente não é por acaso também o destaque concedido a esses e outros personagens ditos ilustres nos números publicados entre 1942 e 1945. Por exemplo, entre os onze exemplares localizados nesse período, Getúlio Vargas é título de quatro notas do jornal, Nereu Ramos cinco, Lauro Müller duas e Duque de Caxias três. Isso considerando apenas as notas que os nomearam já no título e desconsiderando aquelas que fazem alguma referência a eles no corpo do texto, como os concursos de redação, por exemplo. As capas são outros indicativos: a Getúlio Vargas foi concedida a honra do primeiro número, Nereu Ramos foi destaque em outros três números, Duque de Caxias e Lauro Müller foram homenageados com uma capa cada um.

A seleção, o tratamento concedido e os textos a eles relacionados indicam o quanto o jornal e o Grupo Escolar Lauro Müller estavam integrados ao discurso militarista e nacionalista da época. Discurso este que, em consonância com a cruzada eugenista por um lado e a moralista da Igreja Católica por outro, perspectivava a invenção da etnia brasileira ou do processo de modernização e civilização da nação. Esse processo incluía o controle dos corpos, sua docilização, bem como a virilização da raça (Silva; Flores, 2010).

Pode-se afirmar que o jornal $A$ Criança Brasileira tinha poucas colunas fixas, no sentido estrito do termo. As colunas regulares referem-se ao Diário festivo, às Notas sociais e aos Alunos que se distinguem pelo comportamento e pela aplicação, que marcam presença em quase todos os números analisados. Contudo, possuía uma organização e distribuição de notícias que se repetiam, por exemplo: destacar figuras ilustres em textos de tom elogioso na primeira página, datas comemorativas diversas, notas sobre as atividades do Grupo Escolar, que quase sempre indicavam esforço de inserir a escola no rol das atividades importantes que aconteciam extramuros, ou mesmo cartas de pedidos ou agradecimentos a autoridades como Getúlio Vargas, Nereu Ramos, Darcy Vargas, entre outros. Estas certamente tinham a função de revestir de importância às ações do jornal e da escola.

Festas que contavam com a presença de convidados importantes também eram relatadas. Uma nota publicada no jornal de n. 6, em agosto de 1943, é um exemplo. Essa nota informa a realização de uma grande festa na Praça Dias Velho, chamada de $A$ dança da terra, da qual participariam todas as escolas da cidade, incluindo, claro, o Grupo Escolar. O objetivo da festa seria recolher "um pouco da terra histórica, da praia S. Luiz, onde desembarcou Dias Velho, fundador de 'Desterro'" a fim de enviá-la para o Rio de Janeiro: "A capital do Brasil receberá a terra histórica de diversas cidades brasileiras" ( $A$ Criança Brasileira, n. 6, 1943). A festa, que contou com a presença de Nereu Ramos, foi descrita em outro número do jornal:

Alguns alunos vestiram-se de africanos, índios e portugueses. Executaram a dança de seu país e depois recolheram terra para mandar ao Rio de Janeiro. Quem tomou parte nesta festa foram: o Grupo Escolar Dias Velho e o Instituto de Educação. Depois os chefes das três raças hastearam a bandeira. Escutamos também um belo discurso feito por uma aluna do Instituto de Educação. No fim os alunos abriram uma ala para o Dr. Nereu 
Ramos passar. Ele foi inaugurar o Quartel Novo. (Nézia Longari, $3^{\circ}$ ano X, n. $7-8$, nov., 1943, p. 3)

O jornal também evidencia boa rede de relações com o comércio da cidade, haja vista a constância e o número de anúncios publicitários que acompanhavam as principais notícias. O primeiro número contou, por exemplo, com oito anunciantes distribuídos nas quatro páginas do jornal. Depois disso, os números dois e três tiveram quatro e cinco anunciantes, respectivamente. Os demais variaram entre um e três, mas nesse caso os anúncios eram maiores e ocupavam parte significativa de uma página, como toda a barra inferior, por exemplo.

Figura 2

Anúncios publicitários.
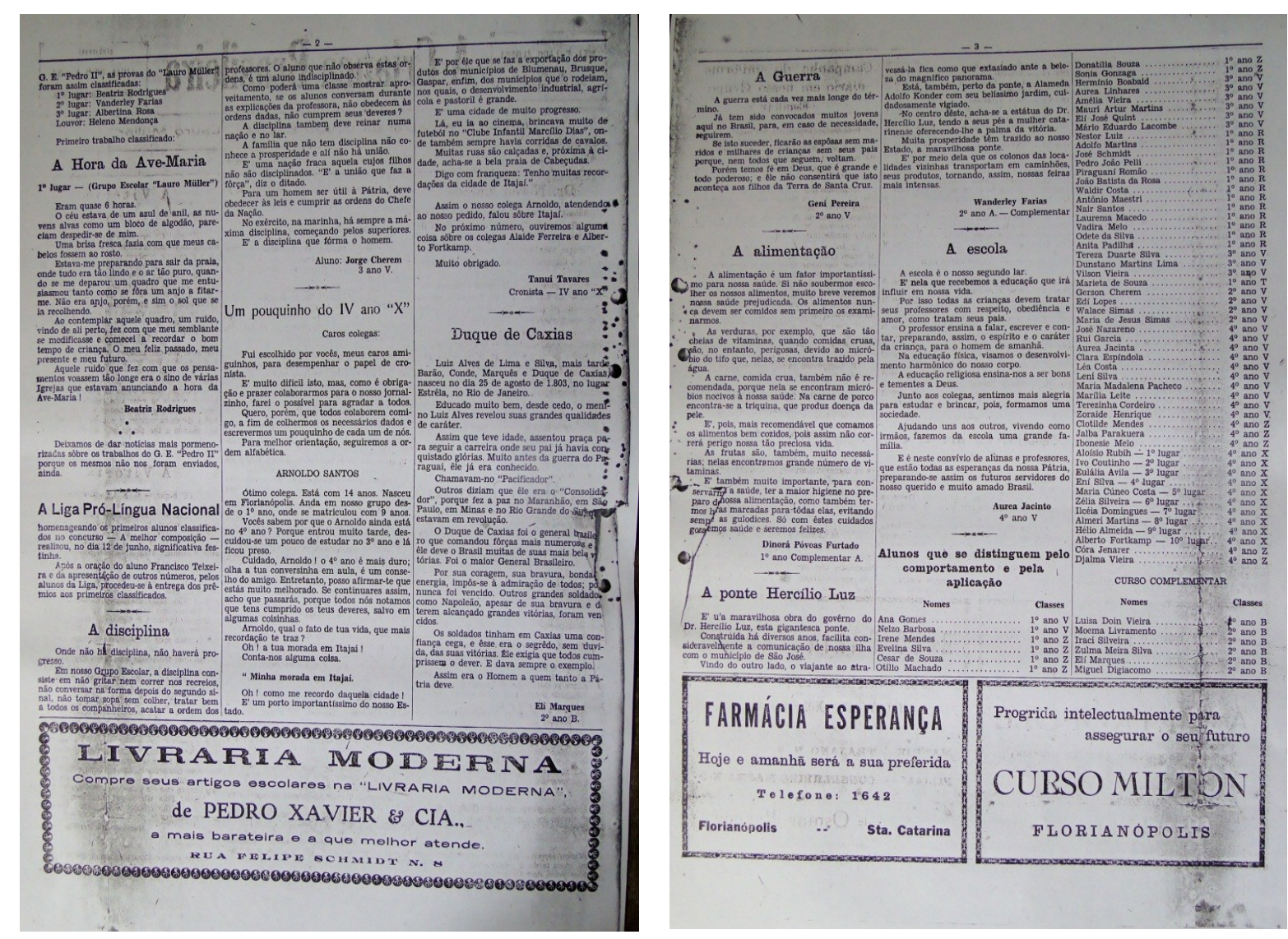

Fonte: A Criança Brasileira, n. 6, ago., 1943.

Convém chamar a atenção para o fato de que, desde o seu primeiro número, textos e notícias aparecem assinados por estudantes, em sua maioria do Curso Complementar, embora houvesse também contribuições de estudantes matriculados no Curso Primário. Nos jornais publicados em 1942, a professora Nilza Puccini Speck ${ }^{8}$ era creditada como orientadora. A partir do número 6, publicado em agosto de 1943, até 1968, não há mais indicação de orientação de professor nos créditos do jornal. Mas claro está que isso não

\footnotetext{
${ }^{8}$ A nota Noivado, publicada no jornal do ano III, n. 9-10, abr., 1944, p. 3, informa que ela se casou e foi nomeada para outro cargo deixando, assim, a escola.
} 
significa, necessariamente, que os professores tenham deixado de exercer esse papel de orientação na organização do periódico.

Não foram encontrados, porém, no arquivo inventariado, documentos que possam fornecer indícios da produção do jornal capazes de elucidar de que forma os professores do Grupo Escolar Lauro Müller estiveram envolvidos em sua organização. Também não se sabe, ainda, como acontecia o processo interno de escolha e distribuição das notas, notícias e reprodução de textos que seriam publicados, nem sobre quais os critérios que balizavam a escolha e exclusão dos textos dos alunos ${ }^{9}$ e de que forma eles conseguiam os anúncios. O que tenho a oferecer são hipóteses, suposições, baseadas na interpretação dos indícios encontrados no próprio jornal e em outros documentos.

A organização estética e política do jornal, a seleção e organização da pauta, a captação de recursos, por meio de anúncios do comércio local, e a impressão em gráfica, no formato próximo ao de tabloide, fornecem indícios de que havia efetiva participação e contribuição de docentes no jornal, bem como de pais de estudantes interessados no valor do periódico para a promoção intelectual de seus filhos e filhas. Um dos indícios dessa hipótese aparece numa nota publicada em 12 de novembro de 1942 e assinada pela redação, que justifica o atraso do jornal:

Apresentamos este mês um exemplar de nosso jornalzinho constando de dois números: 4 e 5 . Houve algum atraso na publicação do jornal e é esse atraso que desejamos justificar. Sendo o mês de agosto dedicado a Caxias procuramos dar o melhor de nossos esforços no sentido de contribuir com bons trabalhos para a exposição inaugurada neste mês. (...)Um outro grande motivo: o elevado aumento de preço do material necessário ao jornal impediu-nos a publicação do mesmo. Agora, porém, graças aos esforços e dedicação da diretora, a aluna Zita Flores, tudo está arrumado. Obtivemos o que nem sequer imaginávamos. Ela falou a respeito dessas dificuldades com seu pai, o jornalista Prof. Altino Flores, que, numa oferta generosa e valiosíssima para nós, deu todo o papel necessário. Aqui deixamos expresso o nosso agradecimento. (A Criança Brasileira, n. 4-5, 1942, p. 2)

Altino Flores, pai da aluna Zita Calado Flores, que até os números 15 e 16 (outubro de 1944) assinava como diretora do jornal, foi jornalista e professor da cidade de Florianópolis, intelectual reconhecido na época. Convém destacar que foi um dos membros fundadores da Academia Catarinense de Letras (1920), da qual Nereu Ramos também participava, e da Associação Catarinense de Imprensa (1932). Para além do presente generoso, é provável de que contribuísse de alguma forma na elaboração do jornal, afinal sua filha era diretora. Muito provavelmente devia lhe interessar esse lugar de projeção intelectual da filha, bem como a reiteração de imagem da escola em que ela estudava como lugar de excelência.

No início da década de 1940, o Grupo Escolar Lauro Müller devia ainda abrigar número significativo de alunos que pertenciam às camadas médias urbanas, crianças bem nascidas, público próximo daquele observado nas décadas de 1910 e 1920, mas

\footnotetext{
${ }^{9}$ A pesquisa prevê a localização de ex-alunos e ex-alunas do Grupo Escolar Lauro Müller que assinaram como diretores, gerentes e repórteres do jornal para realização de entrevistas com o objetivo de melhor realizar essa análise.
} 
também em franco processo de transformação. Na pesquisa realizada por Gladys Teive (2008) sobre normalistas e cultura escolar, o depoimento de dona Glorinha, que cursou o Curso Primário e o Complementar neste Grupo, entre 1918 e 1924, indica que a escola abrigava "a elite, a nata" da cidade (Teive, 2008, p. 65).

No início da década de 1950, porém, outro depoimento informa uma maior heterogeneidade econômica e social entre os estudantes. A professora Isabel da Silva Lins (2002), que começou a trabalhar no Grupo em 1953, escreve que os alunos formavam uma população "bastante heterogênea em todos os aspectos. Havia crianças que vinham de bom meio social e cultural e outras de periferia, algumas apresentando dificuldades e carências" (p. 31). Essa diferenciação certamente incluía hierarquias entre bons e maus alunos, bem como a necessidade de reafirmar e reconstruir a imagem do Grupo como escola modelo, portanto moderna, das décadas de 1910 e 1920.

Pode-se afirmar que o jornal aderiu de forma bastante eloquente às representações relativas ao projeto que se materializava, desde a década de 1930 , no que se referia à afirmação da identidade nacional brasileira. As datas comemorativas eram bem utilizadas nesse sentido, mas uma delas chamou a atenção em especial, porque destacava como memorável o dia 10 de novembro, o dia do Estado Novo.

O Estado Novo foi criado pelo Grande Presidente Vargas nosso valoroso chefe. O dia 10 de novembro de 1937 passou a ser uma data nacional e um marco que assinala o início de uma nova era para o nosso amado Brasil. O Estado Novo veio impulsionar o grande desenvolvimento patriótico e econômico que o Brasil atingira sob o governo de Getúlio Vargas. Há cinco anos que o Brasil goza as vantagens do Estado Novo. No dia $1^{\circ}$ de novembro haverá aqui em nosso Estado uma grande parada em que tomarão parte os Grupos Escolares da nossa Capital. Cada escolar brasileiro tem o dever de comparecer com os melhores uniformes, para melhor homenagear à Pátria. (Jacira Silva, $4^{\circ}$ ano $\mathrm{T}$, ano I, n. 4-5, p. 4)

A constância das referências que exaltavam a Getúlio Vargas e ao Estado Novo, nesse periódico, permite pensar na potente política estado-novista no que diz respeito aos usos dos meios de comunicação, sobretudo os jornais, para fazer propaganda dos projetos do Estado. Nessa direção, destaca-se que o jornal também se manifestava para fazer cumprimentos às autoridades, como o contemplado na capa da edição de abril de 1944: “'A Criança Brasileira' cumprimenta o Interventor Nereu Ramos pela passagem do nono aniversário do seu notável governo". Todo o texto é construído louvando-se a pátria e Nereu Ramos. O contexto da guerra e a necessidade de renúncia e sacrifício por parte dos brasileiros é enfatizada, como se pode observar no excerto abaixo:

A hora é de afirmação e de fé. O Brasil nunca agrediu Nações, nem desrespeitou tratados. Honrou sempre as assinaturas representativas de sua soberania. Nunca se deixou humilhar ou vencer. O passado afirma-lhe o presente e é garantia do futuro. Como pode, em verdade, amar a Pátria e Ihe cultuar dignamente as tradições, o que lhe ignorou de todo ou mal conhece a Língua que Latino Coelho, com irrecusável justeza, dizia ser a mais eloquente revelação da nacionalidade e da independência de um povo. A hora é, portanto, de renúncia e sacrifício. É,sobretudo de confiança e de ação. [...] Dentro no nosso território pequeno para a extensão imensa 
do Brasil palpita um pouco do seu futuro e da sua vida de Nação realmente soberana. (A Criança Brasileira, n. 9-10, abr., 1944, capa)

A clara oposição aos estrangeiros e a fé depositada nos trabalhos de Nereu Ramos e Getúlio Vargas, chefes de governo, pais da nação, e a afirmação da grandeza dos catarinenses, mesmo com o pequeno território, são representações que vão se repetir inúmeras vezes nos números publicados entre 1942 a 1945. Nesses jornais observa-se uma série de atividades que integram a escola às questões políticas, o que evidencia o quanto os investimentos na construção da brasilidade, na formação produtiva do catarinense e sua disciplinarização ocorreram em sintonia com aumento de práticas de intervenção nas escolas. Ao disciplinar os hábitos e normatizar condutas das crianças, a escola seria capaz de "interferir na família, e, através do reordenamento do seu cotidiano, atingir também a comunidade social mais ampla" (Campos, 2004, p. 154).

Em Santa Catarina, a publicação do decreto-lei n. 88, de 31 de março de 1938, pelo então interventor Nereu Ramos, constitui marco de uma mudança bastante significativa nesse processo. A partir dele, desencadearam-se ações mais efetivas que visavam à homogeneização cultural e que atingiram principalmente alemães, italianos e seus descendentes. O decreto concretizou medidas como a proibição do uso de língua estrangeira nas escolas e a criação da Superintendência Geral das Escolas Particulares e Nacionalização do Ensino. Tal proibição se estenderia até mesmo para a esfera privada, num esforço para constituir a brasilidade de Santa Catarina, posta em dúvida em razão da imagem de que convivia com o chamado perigo alemão (Campos, 2004; Fáveri, 2004; Falcão, 2004).

A descrição de um aluno sobre visita realizada a uma Exposição do material de propaganda nazista dá pistas de como o perigo alemão estava sendo ensinado às crianças:

No dia 28 de julho, à tarde, o nosso diretor, sr. Sálvio Oliveira, levou-nos à Secretaria da Ordem Política e Social para vermos a exposição de utensílios de propaganda nazista. Existiam aí: bandeiras de seda, de um lado alemã e de outro lado brasileira; o busto do Hitler feito a canivete; um depósito para selos, em forma de tanque de guerra, tendo em cima a bandeira alemã; alguns quadros feitos com asas de borboleta. Havia, ainda, retratos de Hitler; condecorações com o distintivo alemão; livros, jornais, dicionários, revistas e álbuns, livros escolares ensinando alemão; aparelho radiotransmissor e máquinas de cinema. Encontravam-se também muitas armas alemãs; um canhão de fogo, espingardas, revólveres, pistolas. Visitamos também o presídio onde se encontravam muitos alemães presos. (José Hamilton Duarte Silva, 1ํano CCA, ano I, n. 4-5, capa)

Muito provavelmente os materiais de propaganda expostos foram apreendidos pela polícia quando da prisão de alemães acusados de traidores do Brasil. Ressalte-se que não falar a língua portuguesa já era considerado uma ato de traição à pátria brasileira, ao mesmo tempo em que falar o idioma estrangeiro qualificava o falante: se italiano, fascista; se alemão, nazista (Fáveri, 2004). Chama a atenção também que até mesmo os presos foram visitados pelos alunos. Certamente, como parte da estratégia pedagógica, interessava qualificar a condição dos presos como nazistas e 0 perigo que 
representavam. A constatação de que havia muitos alemães presos informa parte da política adotada no período. A detenção de presos políticos antecedeu inclusive a declaração de guerra à Alemanha e deixou muitas marcas naqueles que foram presos e em seus familiares, como bem demonstrou a pesquisa de Marlene de Fáveri (2004).

A entrada do Brasil na guerra significou o acirramento de tensões e conflitos étnicos, e a construção de um clima de medo no Estado. O jornal, publicado em 12 de novembro de 1942, indica como o Grupo Escolar e a própria cidade de Florianópolis integraram-se a essa nova situação.

A nota $A$ agressão aos nossos navios se atém em confirmar o quanto o Brasil, de Norte a Sul, foi abalado pela notícia de que haviam sido afundados cinco navios brasileiros:

Confirmava-se pelo rádio essa notícia e o povo indignado saía pelas ruas, pedindo justiça e vingança pela morte de tantas vítimas inocentes. O governo do Brasil, na pessoa do eminente Dr. Getúlio Vargas, não trepidou em declarar guerra aos alemães e italianos, bárbaros trucidadores de quase 800 brasileiros, tripulantes e passageiros dos navios afundados. (Nadir Oliveira, $2^{\circ}$ ano, CCB, ano I, n. 4-5, p. 2)

Ao lado dessa notícia, na coluna ao centro da página, segue outra nota intitulada Meus patrícios:

O Brasil atravessa uma hora perigosa. Como brasileiros devemos permanecer calmos e confiar sempre em nosso presidente Getúlio Vargas. $\mathrm{O}$ afundamento dos navios indefesos pelos bárbaros e traiçoeiros do eixo causou, como era natural, grande indignação ao povo brasileiro. O nazismo vinha formando dentro do Brasil uma nova nação. Lutaremos contra os que querem perturbar a nossa paz e destruir a nossa liberdade. Confiar no presidente Getúlio Vargas é dever de todo bom brasileiro, porque ele repetirá qualquer agressão daqueles que pretendem apunhalar o Brasil pelas costas. (Deni B. de Almeida, $1^{\circ}$ ano, CCB, ano I, n. 4-5, p. 2)

Cynthia Machado Campos (2004) destaca que os debates em torno do par nazismo/nacionalismo ganharam força nas décadas de 1930 e 1940 em razão do crescimento do sentimento antigermânico no Brasil, sentimento este ligado, entre outros motivos, à suposta ameaça que os alemães representavam à integridade do território nacional. Todavia cumpre destacar que as formas de percepção dessa ameaça não ocorreram de forma homogênea e linear entre os catarinenses. Hitler e Mussolini alcançaram considerável prestígio nas zonas coloniais, mas também na imprensa catarinense dos anos 1930 "independente de sua filiação partidária, da sua área de circulação ou mesmo da língua em que estava sendo redigida" (Falcão, 2004, p. 182).

Porém, mesmo considerando-se esse aspecto, o perigo alemão em Santa Catarina ganhou contornos mais nítidos na década de 1940, especialmente conforme avançava a guerra na Europa e a força disciplinadora e organizadora das instâncias sociais ganhava impulso sob a tutela do Estado. Nesse momento também se fortalecia a atenção de governantes, políticos e intelectuais catarinenses na importância de se afirmar a brasilidade do Estado. E esta foi afirmada, sobretudo e especialmente, em contraposição aos alemães. 
Mas o projeto de construção de nacionalidade em Santa Catarina contou, no período da guerra, com a instauração de um clima de medo e tensão entre a população. Se exagerado ou não, o certo é que as pessoas pareciam mesmo acreditar ou investir na ideia de que um ataque ao Brasil parecia ser um risco iminente. $\mathrm{O}$ jornal publicado em 12 de novembro de 1942 é um indício. A nota Defesa passiva antiaérea informa sobre a realização de um exercício de defesa ocorrido em Florianópolis, no dia 22 de agosto de 1942, no qual foram distribuídos à população folhetos pelos quais se explicava como se portar durante esse acontecimento. Também os professores do Grupo Escolar fizeram "amplas explicações" recomendando aos estudantes que obedecessem rigorosamente às ordens das autoridades: "Estes exercícios não devem ser tomados como brinquedos, pois visam ensinar ao povo como portar-se durante um ataque real" (A Criança Brasileira, ano 1, n. 4-5, p. 2).

O exercício acima descrito certamente estava ligado à outra política, alvo da nota $O$ blackout em Florianópolis. Ela informa sobre a política de escurecimento da cidade à noite, o consequente recolhimento das pessoas por ordem de Nereu Ramos e sobre exercício na escola, em caso de ataque aéreo:

Em todas as instituições há mais movimento, atualmente. Até nos Grupos fazem-se exercícios de como se deve proceder em caso de ataque aéreo. Assim, começaram as experiências em nosso grupo escolar. Foi mandado limpar o porão onde algumas partes são embaixo de "piso de cimento" e onde nós podemos abrigar. No dia 21 de setembro, nosso diretor, por meio de uma sineta, deu o sinal de alarme. Corremos a fechar as janelas e as portas. Depois, reunidos, fomos todos para o porão. Passados uns minutos soou o sinal de "tudo calmo". Voltamos para as classes. (Auri Rodrigues Alvez, $1^{\circ}$ ano, CCA, ano I, n. 4-5, p. 3)

Nas notas Defesa passiva antiaérea e Blackout em Florianópolis, o que se pode perceber com bastante clareza são práticas que fizeram parte da construção do perigo e do medo na cidade de Florianópolis. Eram boatos, notícias publicadas em diferentes jornais, faladas ou sussurradas entre conhecidos, nas ruas, esquinas, casas. Surgiam e aumentavam sem se saber de onde ou por que exatamente. O que se observa, considerando outros estudos (Fáveri, 2004), é que se tratava de um conjunto difuso de repertórios que corriam as cidades, as casas e as escolas e que deixavam as pessoas inseguras e com medo.

O medo vinha acompanhado de preconceito e racismo, especialmente contra os alemães e seus descendentes ${ }^{10}$. Relações cotidianas modificavam-se e atingiam as escolas de modo contundente. Um desses exemplos pode ser acompanhado na coluna que objetivava fazer conhecer um pouco mais sobre a vida dos alunos. No texto Um pouquinho do IV ano $X$, o aluno Alberto Fortkamp foi assim apresentado:

Como estão vendo, nosso colega tem em sua assinatura uma palavra estrangeira. É costume de muita gente, conforme tenho escutado, chamar

\footnotetext{
${ }^{10}$ Segundo Cynthia Machado Campos (2004, p. 157) "os núcleos poloneses, ucranianos e italianos adquiriram menor vulto no mapa das populações estrangeiras sobre as quais pretendiam intervir". Não obstante isso, na década de 1940 esses grupos também foram perseguidos e alvo da polícia política, principalmente os italianos.
} 
de quinta-coluna a todas as pessoas que assim se assinam. Não! As pessoas com assinaturas estrangeiras, desde que nascidas ou naturalizadas no Brasil, são brasileiros. Pensemos um pouco e olhemos para o patrono do nosso Grupo. Lauro Müller - nome estrangeiro, não é? No entanto foi um grande brasileiro, ocupando importantes cargos. Foi governador de nosso Estado, ministro das Relações Exteriores etc. Sabem onde nasceu? Em Itajaí, cidade catarinense. Viram vocês que não é qualquer pessoa que devemos chamar de quinta-coluna, pois "quintacoluna" quer dizer: "Traidor." (A Criança Brasileira, ano 2, n. 7-8, nov., 1943, p. 2)

Em Santa Catarina, como em outros lugares do país, estrangeiros e descendentes foram colocados sob suspeição pela polícia e pela população. Há diferentes casos de enfrentamentos étnicos relatados na historiografia sobre o tema. Por exemplo: artigos de imprensa apresentavam estrangeiros e seus descendentes como inimigos do país, casas eram apedrejadas e pichadas, era comum haver ofensas públicas, prisões (Fáveri, 2004; Falcão, 2004). Mesmo sem enfrentamentos dessa ordem, sobrenomes estrangeiros, principalmente de origem alemã, não raro eram alvos de adjetivos vários, o preferido parecia ser o de quinta-coluna ${ }^{11}$. Do contrário, não seria notado e alvo de defesa por parte da colega que apresentou Alberto Fortkamp em sua crônica.

Mas o surgimento do jornal $A$ Criança Brasileira, no contexto de recrudescimento da nacionalização, também precisa ser lido como produto da forte influência das propostas defendidas pelo movimento escolanovista e que se difundiam em diferentes regiões do Brasil. Isso porque o jornal era uma prática escolar integrante de um movimento político e educacional que estimulava a implantação das associações auxiliares nas escolas. Também as instituições de ensino privado, de cunho confessional e voltado às elites, foram alvo dessas intervenções. Maria Teresa Santos Cunha (2011), em sua análise do jornal escolar Pétalas, produzido pelas alunas do Curso Primário do Colégio Coração de Jesus, estabelecimento de ensino religioso feminino em Florianópolis, observou que o jornal, criado para dar visibilidade ao colégio e a suas alunas, também parecia atender às demandas das políticas instituídas no Estado.

As associações auxiliares foram instituídas no ensino primário ainda na década de 1930. O Departamento de Educação, criado em 1935, em Santa Catarina, elencava quais seriam essas associações e suas respectivas finalidades, bem como de que maneira deveriam ser organizadas. Elas foram normatizadas no ano de 1944, com a vigência do decreto-lei n. 2.991/44, que enfatizava os objetivos dessas associações, voltadas à preparação de futuros cidadãos para a sociedade moderna (Otto, 2012). Dessa forma, desde o início do século 20 até por volta do fim da década de 1960, foram instituídas as seguintes associações auxiliares da escola, não necessariamente nesta ordem: liga prólíngua nacional, caixa escolar, cooperativa escolar, clube agrícola, pelotão de saúde, biblioteca escolar, jornal escolar, clube de leitura, liga da bondade, círculo de pais e

\footnotetext{
${ }^{11}$ Termo aparecido durante a guerra civil espanhola e usado para designar aqueles que, em Madrid, apoiavam as quatro colunas que marchavam contra o governo da Frente Popular Republicana do presidente Azaña. Durante a Segunda Guerra foi utilizado para referir-se àqueles que agiam sub-repticiamente num país em guerra, ou em vias de entrar na guerra, preparando ajuda em caso de invasão ou fazendo espionagem e propaganda em favor do Eixo. Cf. <http://cpdoc.fgv.br/producao/dossies/AEraVargas1/ glossario/quinta coluna>. Acesso: 6 set., 2012.
} 
professores, orfeão escolar, museus escolares e centros de interesse. Essas associações eram práticas escolares que tinham como objetivo permitir que as crianças vivenciassem situações semelhantes aos acontecimentos vividos em sociedade, preparando-os para a vida (Otto, 2012).

O número 1 do jornal informa no Diário festivo (n. 1, 1ํ maio, 1942, capa) que a fundação do jornal ocorreu numa festa interna, no dia 25 de março, "Dia da Criança", em conjunto com a "criação das associações periescolares". Em outra seção, intitulada O dia da criança, descreve-se entre os acontecimentos do dia que "foram criadas diversas instituições como: Liga Pró-Língua Nacional, Clube de Leitura, Orfeão e o Jornal” (n. 1, 1ํㅡㄴ maio, 1942, p. 3).

No relatório de inspeção escolar no Grupo Lauro Müller, de 18 de agosto de 1942, feito pelo inspetor Adriano Mosimann, um dos itens avaliados foi justamente as associações escolares. Segundo o relatório, existiam as seguintes associações no Grupo: Cooperativa, Caixa Escolar, Clube da Leitura, Biblioteca, Pelotão de Saúde, Liga PróLíngua Nacional, Jornal, Sopa Escolar e Liga da Bondade. Faltando ainda, Círculo de País e Mestres e Clube Agrícola. Suas ações foram assim descritas pelo inspetor: "Percebi pela escrituração e pelos álbuns, que as associações estão em atividade, embora a preocupação da próxima exposição de trabalhos tenha, momentaneamente, as relegado para segundo plano" (Relatório de inspeção, 18 ago., 1942 ${ }^{12}$ ).

O jornal enfatiza e valoriza as atividades das associações do Grupo Escolar em suas páginas, mas nenhuma delas alcançou tanto destaque quanto a Liga Pró-Língua Nacional, que aparece em quase todos os números e mais de uma vez, seja anunciando novos concursos - declamação, poesia, redação -, seja publicando resultados de concursos anteriores ou relatando festas por ela organizadas ou patrocinadas na escola. Em agosto de 1943, o n. 6 do jornal teve a capa quase toda ocupada pelo concurso promovido pela Liga Pró-Língua Nacional entre os alunos do $2^{\circ}$ ano do Curso Complementar dos grupos Lauro Müller e Luiz Delfino. Na verdade, foi uma competição entre os grupos escolares organizada pelas professoras de Língua Portuguesa.

Outra atividade bastante significativa intitulou-se Concurso de férias, cujo resultado contou com prêmio em dinheiro para os três primeiros colocados:

Finalmente temos o prazer de levar ao conhecimento de nossos queridos leitores o resultado do Concurso de Férias, patrocinado pela Liga PróLíngua Nacional. A classificação, como já dissemos em número anterior, foi muito demorada em virtude do grande número de concorrentes. Concluída a apuração foram classificados os contos dos seguintes alunos: 1ํ lugar: Marília Leite - $2^{\circ} \mathrm{B} ; 2^{\circ}$ lugar: Eulália Ávila - 1ํano B; $3^{\circ}$ lugar: Ana de Paula - $1^{\circ}$ ano A. Conforme foi instituído no concurso esses alunos receberão respectivamente os prêmios de $\operatorname{Cr} \$ 20,00, \operatorname{Cr} \$ 15,00$ e $\operatorname{Cr} \$$ 10,00. (A Criança Brasileira, ano IV, n. 25-26, nov., 1945, p. 3$)^{13}$

\footnotetext{
${ }^{12}$ Acervo Museu da Escola Catarinense - Udesc.

${ }^{13}$ Foi a primeira vez que prêmio em dinheiro foi publicizado. No número 15-16, de outubro de 1944, existe um anúncio da Cooperativa da escola, Cooperativa Flordoardo Cabral, pelo qual é possível dimensionar o poder de compra do prêmio recebido pelas crianças vencedoras: uma pena: $\operatorname{Cr} \$ 0,20$. Caderno de linguagem com 24 folhas: Cr\$ 1,00. Lápis Faber: Cr\$ 0,30.
} 
Tamanho destaque dado pelo jornal à Liga Pró-Língua Nacional, "valiosa instituição que visa intensificar o gosto pelas coisas da nossa língua e da terra" (A Criança Brasileira, n. 1, 1942, p. 2), justifica-se pela grande preocupação que a língua e seu uso suscitavam no Estado Novo. A palavra escrita e a falada eram mantidas sob o controle do Departamento de Imprensa e Propaganda - DIP - pois a uniformidade do uso da língua ou da dicção era parte de uma política controladora ligada à construção da nacionalidade. A normatização da língua foi o eixo central que orientou a intervenção escolar do governo Nereu Ramos e as práticas daí advindas, de imposição da língua nacional, indicam elementos de um "verdadeiro culto à linguagem" (Campos, 2004, p. 165).

As atividades da Liga Pró-Língua Nacional indicam o empenho da escola em se adequar a essa política da língua. Evidenciam também o quanto ela se distinguia das demais ligas e produzia distinções ao travar competições entre escolas, entre alunos, afinal tais competições davam visibilidade à escola e aos seus estudantes e professores. Essas práticas escolares, nas quais se inclui o jornal, mantinham o Grupo Escolar Lauro Müller em evidência na década de 1940.

\section{O jornal e o passado}

Claro está que o jornal A Criança Brasileira, assim como qualquer outro documento selecionado para compor o quadro de referências da análise histórica, nunca terá uma relação direta com as práticas que designa (Chartier, 2011). Contudo, esse periódico certamente é capaz de fornecer representações de práticas que possuíam razões, códigos, finalidades e destinatários específicos que dão a ler e interpretar as marcas e interesses sociais de seu tempo.

Ao longo de 21 anos, apenas os localizados conforme o quadro um, o jornal selecionou e publicou notícias relacionadas ao cotidiano da escola: movimento de matrículas, festas internas e notas sociais, os aniversariantes do mês, casamentos ou noivados de professoras, lista de alunos que se distinguiam pelo comportamento e pela aplicação, concursos e outras ações empreendidas pelas associações auxiliares da escola. Reproduziu textos de cunho moral, cívico e higienista e uma variedade grande de notícias assinadas pelos alunos que faziam referências às questões políticas locais, estaduais e nacionais.

Também se pode observar a importância que esses impressos periódicos alcançavam no período. É certo que sua circulação não ficava reduzida apenas a escola que produzia o jornal. Muito provavelmente eles circulavam nas casas dos estudantes, de professores, familiares e em outras instituições escolares. Há várias notas publicadas que evidenciam a circulação dos jornais, como a informação de que $A$ Criança Brasileira havia sido remetida aos grupos escolares do Estado: "dos quais temos recebido expressões de simpatia e agradecimento". E também o projeto de enviar mais exemplares para "diversos professores dos Estados do Maranhão, Alagoas, Espírito Santo, Goiás, Rio de Janeiro e Paraná" (A Criança Brasileira, n. 2, 5 jun., 1942, p. 4).

Em outra nota, na mesma página, sob o título Impressões, foram publicados trechos de cartas de diretores de grupos escolares do interior do Estado, que agradeciam o envio do jornal e registravam sua qualidade. O prof. Hercílio de Fáveri, diretor do Grupo Escolar Barão do Rio Branco, de Urussanga, escreve: "Acuso o recebimento do 1ํㅡúmero de "A 
Criança Brasileira". Meus Parabéns! Um jornal impresso, em Grupo Escolar, mesmo na capital do Estado, é algo que devemos admirar". Alguns desses diretores, ao agradecer, também aproveitavam para enviar o jornal de sua escola, como o jornal Brasil, enviado pela professora Vanda B. Cláudio, diretora do Grupo Escolar Raulino Horn, de Indaial. "É um jornalzinho manuscrito com perfeição e que muito nos agradou" ( $A$ Criança Brasileira, n. 2, 5 jun., 1942, p. 4). Em outra ocasião, publicou-se nota de agradecimento aos grupos escolares Cruz e Souza e Arquidiocesano São José pelo "jornalzinho de agosto que nos enviaram" (A Criança Brasileira, n. 6, ago., 1943, p. 4). A circulação desses periódicos dava visibilidade às atividades escolares, aos sujeitos a elas relacionados e, mais que isso, Ihes conferia distinção.

Em sua pesquisa sobre o jornal Nosso Esforço, Ana Regina Pinheiro (2008) já havia observado a ampla repercussão dos jornais escolares e a popularidade dessa atividade não apenas no Brasil, mas em outros países da América Latina, sobretudo no Uruguai e na Argentina. Ela encontrou jornais dispersos de outras escolas no acervo do jornal Nosso Esforço, concentrados, em sua maior parte, nas décadas de 1930 e 1940. Isso evidencia o incentivo das políticas públicas para a produção desses periódicos nas escolas primárias, que não se reduzem a apenas uma região. Esta é uma das questões muito pouco ou quase nada exploradas: pensar a produção desses jornais escolares num quadro político mais amplo, no Brasil e também na América Latina, a fim de encontrar pontos de contato e de distanciamento.

Certamente, muitas questões ficaram em aberto neste artigo, mesmo recortando-se a análise para apenas quatro anos de publicação do jornal. Isso reitera a ideia de que os jornais escolares e a imprensa de educação e ensino, de modo geral, constituem-se em instrumentos privilegiados para se observarem práticas e representações que as designam. Os jornais dialogam com seu tempo, sendo, portanto, fontes que permitem historicizar prescrições e orientações diversas, como aquelas voltadas ao bom comportamento, aos bons costumes, às boas leituras, entre outras normatividades. Permitem problematizar, descrever e narrar práticas instituídas nas escolas, modos de saber e fazer de sujeitos que em seu cotidiano, em seu tempo, apropriaram-se, negaram ou integraram projetos políticos.

Os jornais foram produzidos por um coletivo de sujeitos para outras coletividades. Permitem, portanto, a visada de sujeitos de outro tempo, sujeitos que construíram em seu presente um projeto de futuro comum, futuro passado que nos interessa, pois possibilita fazer questionamentos, olhar de novo às escolhas feitas e os itinerários percorridos. Exercício capaz de permitir reelaboração de orientação no tempo, de revisão de expectativas futuras sobre o lugar da escola, sobre as intersecções entre práticas políticas e escolares.

Para Paul Ricoeur (2007), existiria uma aporia da verdade na História que residiria na própria capacidade que o discurso histórico possui de reconstruir o curso passado dos acontecimentos. As expectativas e exigências dessa intencionalidade historiadora, representação presente do passado ausente, foi chamada por Ricoeur de "representância" (2007, p. 289). Esta elevaria ao plano da epistemologia da operação historiográfica o enigma da representação do passado, haja vista que o que passou não 
voltará mais. O passado é o ausente na História, tornado presente pela memória e por diferentes regimes de representação.

$\mathrm{Na}$ operação historiográfica, o passado só pode ser alcançado no presente do passado, isto é, através dos vestígios que se tornaram documentos para o historiador. Mas isso não significa afirmar que o passado não ocorreu, que ele não é verdade; significa apenas que o discurso histórico não possui meios para recuperá-lo tal como ele foi. O que podemos fazer é buscar os indícios, os rastros, perscrutá-los, torná-los evidências empíricas e fazer escolhas do que será por fim interpretado. Foi o que tentei fazer aqui.

\section{Referências}

ABREU, Martha; SOIHET, Raquel e GONTIJO, Raquel (orgs.). Cultura politica e leituras do passado: historiografia e ensino de história. Rio de Janeiro: Civilização Brasileira, 2007.

BASTOS, Maria Helena Câmara. As revistas pedagógicas e a atualização do professor: a Revista do Ensino do Rio Grande do Sul (1951-1992). In: CATANI, Denice Bárbara; BASTOS, Maria Helena Câmara (orgs.). Educação em revista: a imprensa periódica e a história da educação. São Paulo: Escrituras, 2002, p. 47-75.

BERSTEIN, Serge. A cultura política. In: RIOUX, Jean-Pierre; SIRINELLI, Jean-François (orgs.). Para uma história cultural. Lisboa: Estampa, 1998, p. 349-363.

CAMPOS, Cynthia Machado. As intervenções do Estado nas escolas estrangeiras de Santa Catarina na era Vargas. In: BRANCHER, Ana (org.). História de Santa Catarina: estudos contemporâneos. Florianópolis: Letras Contemporâneas, 2004, p. 149-151.

CERTEAU, Michel de. A escrita da história. Rio de Janeiro: Forense Universitária, 1982.

CHARTIER, Roger. Defesa e ilustração da noção de representação. Fronteiras, Dourados, v. 13, n. 24, 2011, p. 15-29.

CUNHA, Maria Teresa Santos. Mensageiro de sociabilidades: estudo sobre um jornal escolar infantil (Florianópolis, 1946-1952). In: MORGA, Antônio Emílio (org.). História, cidade e sociabilidade. Itajaí: Casa Aberta, 2011, p. 235-250.

FALCÃO, Luiz Felipe. A guerra interna (integralismo, nazismo e nacionalização). In: BRANCHER, Ana (org.). História de Santa Catarina: estudos contemporâneos. Florianópolis: Letras Contemporâneas, 2004, p. 167-198.

FÁVERI, Marlene de. Memórias de uma (outra) guerra: cotidiano e medo durante a Segunda Guerra em Santa Catarina. Itajaí: Univali; Florianópolis: UFSC, 2004.

FERNANDES, Rogério. Cultura de escola: entre as coisas e as memórias. Pro-posições, v. 16, n. 1, 2005, p. 19-39.

GOMES, Ângela de Castro. Cultura política e cultura histórica no Estado Novo. In: ABREU, Martha; SOIHET, Raquel; GONTIJO, Raquel (orgs.). Cultura política e leituras do passado: historiografia e ensino de história. Rio de Janeiro: Civilização Brasileira, 2007, p. 43-63.

JORNAL A CRIANÇA BRASILEIRA. Órgão mensal do grupo Escolar Lauro Müller, 1942 a 1945. Acervo Museu da Escola Catarinense - Udesc.

JULIA, Dominique. A cultura escolar como objeto histórico. Revista Brasileira de História da Educação. São Paulo: SBHE, n. 1, 2001, p. 9-43. 
LE GOFF, Jacques. História e memória. Campinas: Unicamp, 2003.

LINS, Isabel da Silva. O valor da experiência: o relato de uma vida dedicada à educação. Florianópolis: do Autor, 2002.

LUCA, Tânia Regina de. História dos, nos e por meio dos periódicos. In: PINSKY, Carla Bassanezi (org.). Fontes históricas. São Paulo: Contexto, 2006, p. 111-153.

OTTO, Franciele. As associações auxiliares da escola e a forma de transmissão das dimensões valorativa e moral da sociedade catarinense: o caso das Ligas da Bondade (1935-1950). São Paulo: USP, 2012. 213f. Dissertação (mestrado em Educação). Faculdade de Educação. Universidade de São Paulo.

PINHEIRO, Ana Regina. Escola Caetano de Campos: escola paulista, escola vanguardeira. Campinas: Unicamp, 2008. 219f. Tese (doutorado em Educação). Programa de Pós-Graduação em Educação. Universidade de Campinas.

RELATÓRIO DE INSPEÇÃO ESCOLAR. In: Livro de visitas de autoridades escolares do Grupo Escolar Lauro Müller, 18 de agosto de 1942. Acervo Museu da Escola Catarinense - Udesc.

RICOEUR, Paul. A memória, a história, o esquecimento. Campinas: Unicamp, 2007.

SILVA, Cristiani Beretada; FLORES, Bernardete Ramos. Gênero e nação: a Série Fontes e a virilização da raça. História da Educação, Pelotas: Asphe, v.14, n. 32, 2010, p. 77-108.

TEIVE, Gladys Mary Ghizoni. Uma vez normalista, sempre normalista: cultura escolar e produção de um habitus pedagógico (1911-1935). Florianópolis: Insular, 2008.

TEIVE, Gladys Mary Ghizoni; DALLABRIDA, Norberto. A escola da república: os grupos escolares e a modernização do ensino primário em Santa Catarina (1911-1918). Campinas: Mercado de Letras, 2011.

CRISTIANI BERETA DA SILVA é doutora em História Cultural pela Universidade Federal de Santa Catarina, professora do Departamento de História e dos programas de Pós-Graduação em História e em Educação na Universidade do Estado de Santa Catarina. Bolsista produtividade do CNPq.

Endereço: Avenida Madre Benvenuta, 2007, 88035-001 - Florianópolis - SC - Brasil. E-mail: cristianibereta@gmail.com.

Recebido em 7 de agosto de 2012.

Aceito em 29 de novembro de 2012. 